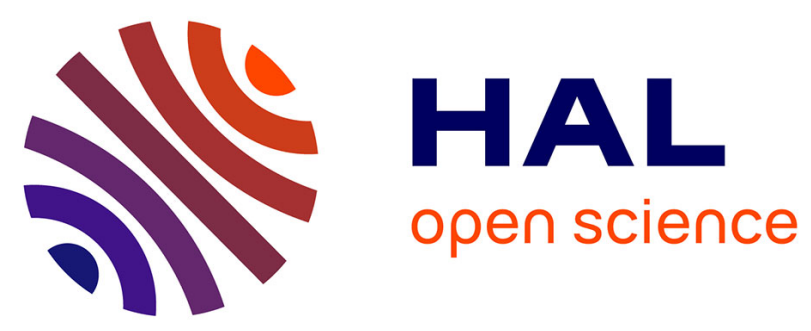

\title{
Dry Coating of Talc Particles: Effect of Material and Process Modifications on Their Wettability and Dispersibility
}

\author{
Guillaume Lefebvre, Laurence Galet, Alain Chamayou
}

\section{To cite this version:}

Guillaume Lefebvre, Laurence Galet, Alain Chamayou. Dry Coating of Talc Particles: Effect of Material and Process Modifications on Their Wettability and Dispersibility. AIChE Journal, 2011, 57 (1), pp.79-86. 10.1002/aic.12239 . hal-01593330

\section{HAL Id: hal-01593330 https://hal.science/hal-01593330}

Submitted on 26 Apr 2019

HAL is a multi-disciplinary open access archive for the deposit and dissemination of scientific research documents, whether they are published or not. The documents may come from teaching and research institutions in France or abroad, or from public or private research centers.
L'archive ouverte pluridisciplinaire HAL, est destinée au dépôt et à la diffusion de documents scientifiques de niveau recherche, publiés ou non, émanant des établissements d'enseignement et de recherche français ou étrangers, des laboratoires publics ou privés. 


\title{
Dry Coating of Talc Particles: Effect of Material and Process Modifications on Their Wettability and Dispersibility
}

\author{
Guillaume Lefebvre, Laurence Galet, and Alain Chamayou \\ Ecole Nationale Supérieure des Techniques Industrielles et des Mines d'Albi-Carmaux, \\ Centre RAPSODEE, Campus Jarlard, 81013 Albi, France
}

Even though dispersion operations have been the object of several investigations, the importance of the different parameters and especially the physicochemical and sur-face properties are rarely treated. Dry particle coating can be used to create new gen-eration materials. In such processes, host particles are mechanically coated with guest particles, without using solvents and subsequent drying, to create new functionalities or to improve initial characteristics. This study examines the surface properties of talc particles modified by dry coating with hydrophobic silica particles. Two parameters have been studied: the concentration of silica particles and the dry coating processing time. Both parameters allow modifications of the work of adhesion of talc particles with water, which is a characteristic of wettability. This change of wettability can consequently influence the dispersion rate of talc in water.

Keywords: talc, dry coating, wettability, work of adhesion, dispersion

\section{Introduction}

The operating parameters involved in the process of dispersing of powders in liquids have been the object of several studies, and in particular, the roles of the steps of stirring and mixing are well understood. ${ }^{1,2}$ However, studies of the influence of the work of adhesion, a key parameter in solidliquid interactions, on the dispersibility of powders are more rare. ${ }^{3}$ At the same time, the determination of the surface energy of powders from contact angle measurements is the subject of a growing number of studies. ${ }^{4-6}$ The objective here is to study the effect of the wettability of talc particles (modified by the presence of hydrophobic silica) on their dispersion in water. Talc powder has been used, because it is widely used in many industrial areas such as paper, paints, ceramics, cosmetics, and pharmaceutics; moreover, talc is in-

\footnotetext{
This work was presented at the 2009 conference of the French Chemical Engineering Society (Marseille, SFGP 2009).

Correspondence concerning this article should be addressed to G. Lefebvre at guillaume.lefebvre@mines-albi.fr.
}

soluble in water making it a good model material for this study.

For economic and environmental reasons, dry particle coating is a very promising method for the surface modification of industrial powders as it does not involve solvents and subsequent drying. ${ }^{7-9}$ Powdered material with a relatively large particle size (host particles; $1-500 \mu \mathrm{m}$ ) are mechanically coated with fine particles (guest particles; 0.01-50 $\mu \mathrm{m}$ ) to create new functionalities or to improve their initial characteristics. ${ }^{10}$ The guest particles are necessarily small so that Van der Waals interactions are strong enough to obtain a stable ordered mixture, and the mechanical forces applied by the coating device makes them become firmly attached to the larger host particles. Either a discrete or a continuous coating of guest particles can be achieved depending on the operating conditions such as processing time, mechanical action, weight fraction of guest to host particles, and the physical properties of the particles used. ${ }^{11}$ Typical applications of dry coating include the modification of flowability, wettability (hydrophobic/hydrophilic properties), solubility, 


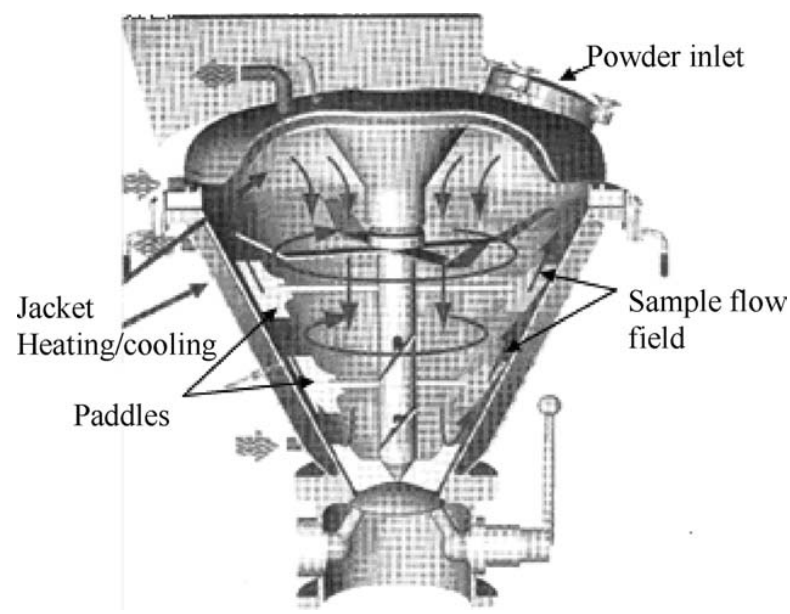

Figure 1. A Cyclomix high shear mixer.

dispersibility, flavor, etc. Figure 1 shows the equipment used in this study for dry particle coating.

In a previous study on the kinetics of the dispersion of talc powder in liquids, Galet et $\mathrm{al}^{3}$ showed that there is a relationship between the optimum stirring power and the total work of dispersion of talc. This study is extended here by examining the effects of changes in surface properties of talc powder by dry coating with silica nanoparticles. This type of silica has two useful properties. First, surface coating by nanosilica guest particles brings about only a negligible change in size of the talc host particles. Second, because of their very small size and their low refraction index, these silica particles are not detectable by the optical fiber used for the dispersion kinetics measurements (see Experimental section) and do not interfere with the measurement signal. The hydrophobicity of talc particles modified by coating with silica has been estimated from contact angles measurements of the different samples with pure water.

\section{Materials and Methods \\ Powders and their characterization}

Talc, $\left[\mathrm{Mg}_{3} \mathrm{Si}_{4} \mathrm{O}_{10}(\mathrm{OH})_{2}\right]$, is a hydrated magnesium sheet silicate with a lamellar structure. Fine talc powders with narrow particle size distributions are generally obtained by air jet milling and turbo classification. As grinding can change the surface properties of particles, a single type of talc from the Luzenac mine in France has been used. The particle size $\left(d_{50}=7 \mu \mathrm{m}\right)$ of this talc has been determined using a Malvern Mastersizer 2000 (dry dispersion in air). Its specific surface area, calculated with the BET model using a Micrometrics ${ }^{\circledR}$ Asap 2010, is $5.2 \mathrm{~m}^{2} / \mathrm{g}$. Aerosil R972 ${ }^{\circledR}$ silica with a specific surface area of $114 \mathrm{~m}^{2} / \mathrm{g}$ was supplied by Degussa. Its surface is modified by dimethyldichlorosilane to make it hydrophobic. The true solid densities of talc and Aerosil R972 ${ }^{\circledR}$ were obtained using a Micrometrics AccuPyc 1330 helium pycnometer, they are, respectively, 2.75 and 1.95 $\mathrm{g} / \mathrm{cm}^{3}$.

The uncoated and coated talc particles were observed with a scanning electron microscope (SEM) to examine the surface morphology and particle shapes before and after coating. The lamellar shape of talc particles can be seen on Figure $2 \mathrm{a}$, whereas Figure $2 \mathrm{~b}$ shows highly agglomerated silica particles (agglomerate size $=250 \mathrm{~nm}$ ). The primary particle size is about $16 \mathrm{~nm}$ (Degussa data).

\section{Coating process}

A Cyclomix vertical high shear mixer has been successfully used to carry out coating. ${ }^{7,8,11}$ The apparatus used here was supplied by Hosokawa Micron with a nominal volume capacity of $1 \mathrm{~L}$. Industrial versions are available with capacities of up to $1 \mathrm{~m}^{3}$. The working principle of the Cyclomix differs markedly from other mixing techniques by the specific interaction between the product being mixed and vessel wall. The powders (host and guest particles) are loaded at the top of the conical mixing vessel to a filling ratio of $66 \%$. The high rotation speed of the paddles $(2240 \mathrm{rpm})$ forces the particles to the wall where the conical shape of the vessel forces the product from the lower to the upper zone of the vessel. At the top, the product flows inward and downward into the center of the vessel. This flow pattern gives fast macromixing. During the upward motion, the particles are accelerated by the paddles and intensively mixed by friction with vessel wall. At the end of the process, the totality of the powder (talc + silica) contained in the Cyclomix is recovered and analyzed. To study the influence of silica concentration, a processing time of $10 \mathrm{~min}$ was used and the values of the silica concentration were in the range from 0 to $10 \mathrm{wt} \%$. To study the effect of the processing time, the silica concentration was fixed at $3 \%$ and the processing times were varied from 1 to $60 \mathrm{~min}$.
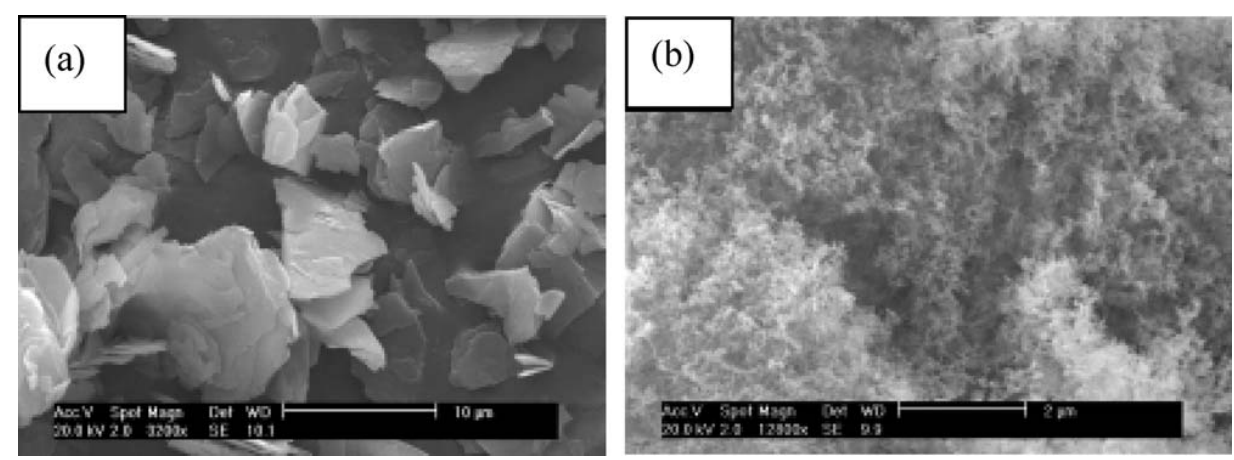

Figure 2. (a) Talc particles $(\times 3200)$ and $(b)$ Aerosil $R 972$ particles $(\times 12,600)$. 


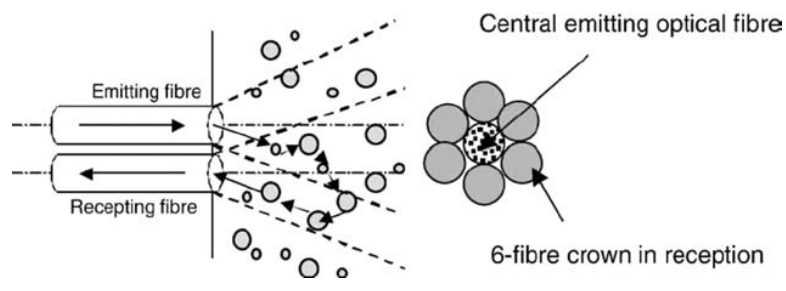

Figure 3. Schematic view of the optical fiber sensor.

\section{Wettability measurements}

The contact angles of the powders were measured by the sessile drop method (ILMS-GBX tensiometer) by deposing a small drop (five drops per sample) of $10 \mu \mathrm{L}$ of pure water on tablets formed from powder. The tablets were made by a compression under a load of $30 \mathrm{kN}$ using an Instron ${ }^{\circledR}$ press. The shape of the drops was observed and used to determine the contact angles. These contact angles values, $\theta$, and the surface tension of the water $\left(\gamma_{\mathrm{LV}}=72.8 \mathrm{~mJ} / \mathrm{m}^{2}\right)$ were used to calculate the work of adhesion, $W_{\mathrm{a}}$, of the samples using Eq. 1:

$$
W_{\mathrm{a}}=\gamma_{\mathrm{LV}}(1+\cos \theta)
$$

\section{Dispersion kinetics}

Measurements of dispersion kinetics of uncoated and coated talc particles in water were performed using a three baffled stainless steel reactor $(10.5 \mathrm{~cm}$ diameter) with a 3.5 $\mathrm{cm}$ diameter dispersion stirrer (deflocculating). The weight percentage of particles added in the water is $0.5 \%$. An optical fiber sensor was used to measure the dispersion rate of particles in water. This noncommercial device was developed at Polytech'Marseille for the determination of particle concentrations in suspension by measuring light backscattering by the particles (see Bergougnoux et al. ${ }^{12}$ for more information). The optical fiber sensor comprises a bundle of

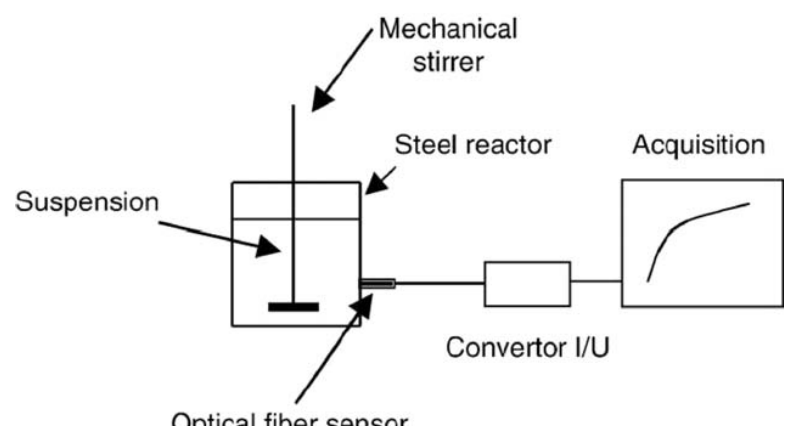

Optical fiber sensor

Figure 4. Schematic view of the experimental setup.

seven fibers. The central fiber carries light into the liquid from an external LED source and the six other fibers are used to detect the backscattered light (see Figure 3). The sample volume analyzed by the sensor is from 5 to $10 \mathrm{~mL}$ depending on the suspension concentration. The sensor is used in conjunction with a signal conditioner and a PC with Labview ${ }^{\circledR}$ data acquisition software (see Figure 4). The light intensity, collected by the crown of receiving fibers, is a function of the volume fraction of the dispersion and the scattering properties of particles (size, shape, and refraction index). For a given concentration of particles, the signal decreases when the particles' size increases. ${ }^{13}$

Preliminary studies ${ }^{13}$ show that the position of the sensor in the reactor has no influence on the relative dispersion kinetics. In our experiments, the sensor was located in the side wall at $2 \mathrm{~cm}$ from the bottom of the reactor. The linearity of sensor response to changes in solids' concentration has been validated in separate experiments and the sensor calibrated to determine the response to a given concentration of powder. The maximum response when the powder is fully dispersed is used to normalize the results of each experiment to give fractional dispersion values. At the end of an experiment, to ensure that the signal obtained corresponds to total dispersion, the stirring speed is increased to the maximum to
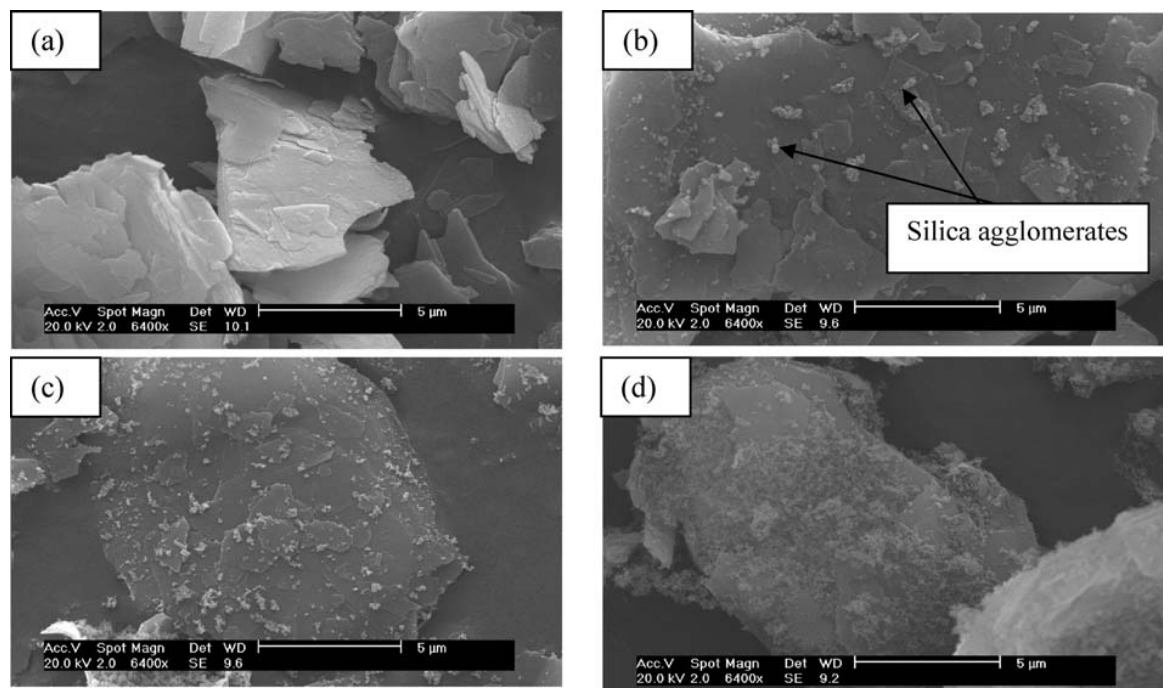

Figure 5. SEM pictures $(\times 6400)$ of the effect of silica concentration: uncoated talc particles (a) and coated particles with $2 \%$ (b), $5 \%$ (c), and $10 \%$ (d) silica. 

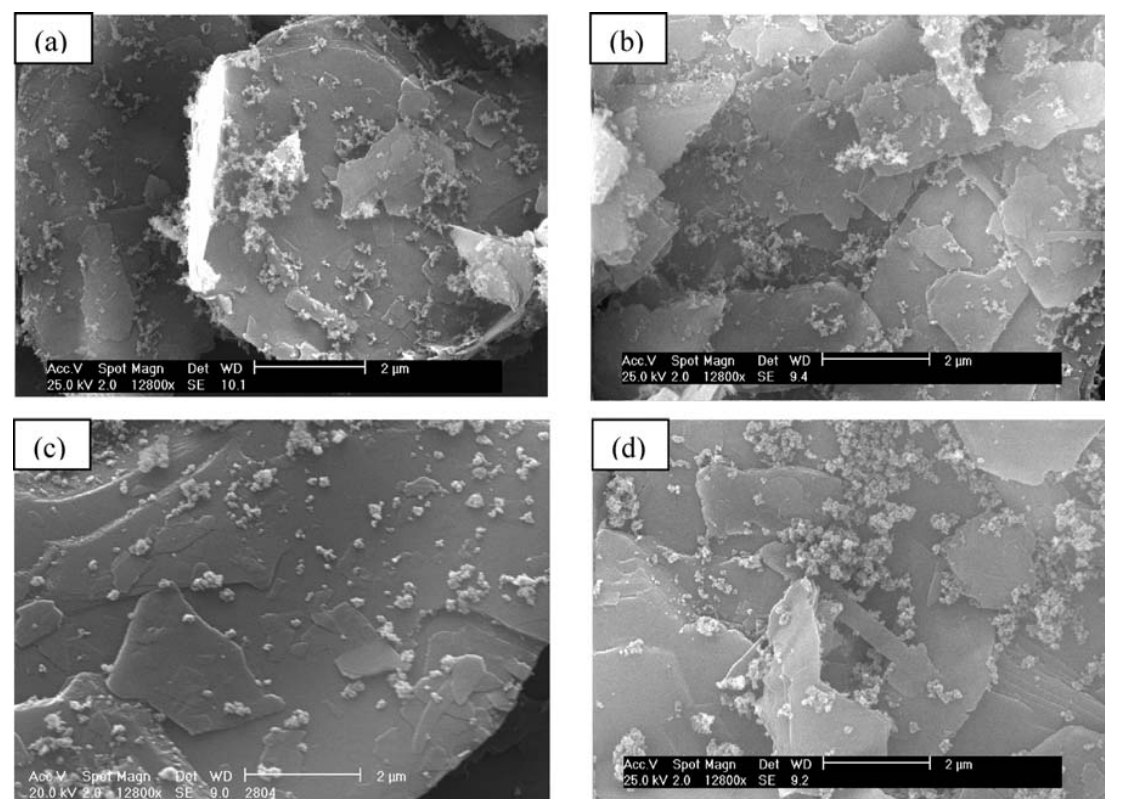

Figure 6. SEM pictures $(\times 12,800)$ of the effect of processing time: $1 \mathrm{~min}(\mathrm{a}), 2 \mathrm{~min}(\mathrm{~b}), 5 \mathrm{~min}$ (c), and $10 \mathrm{~min}$ (d).

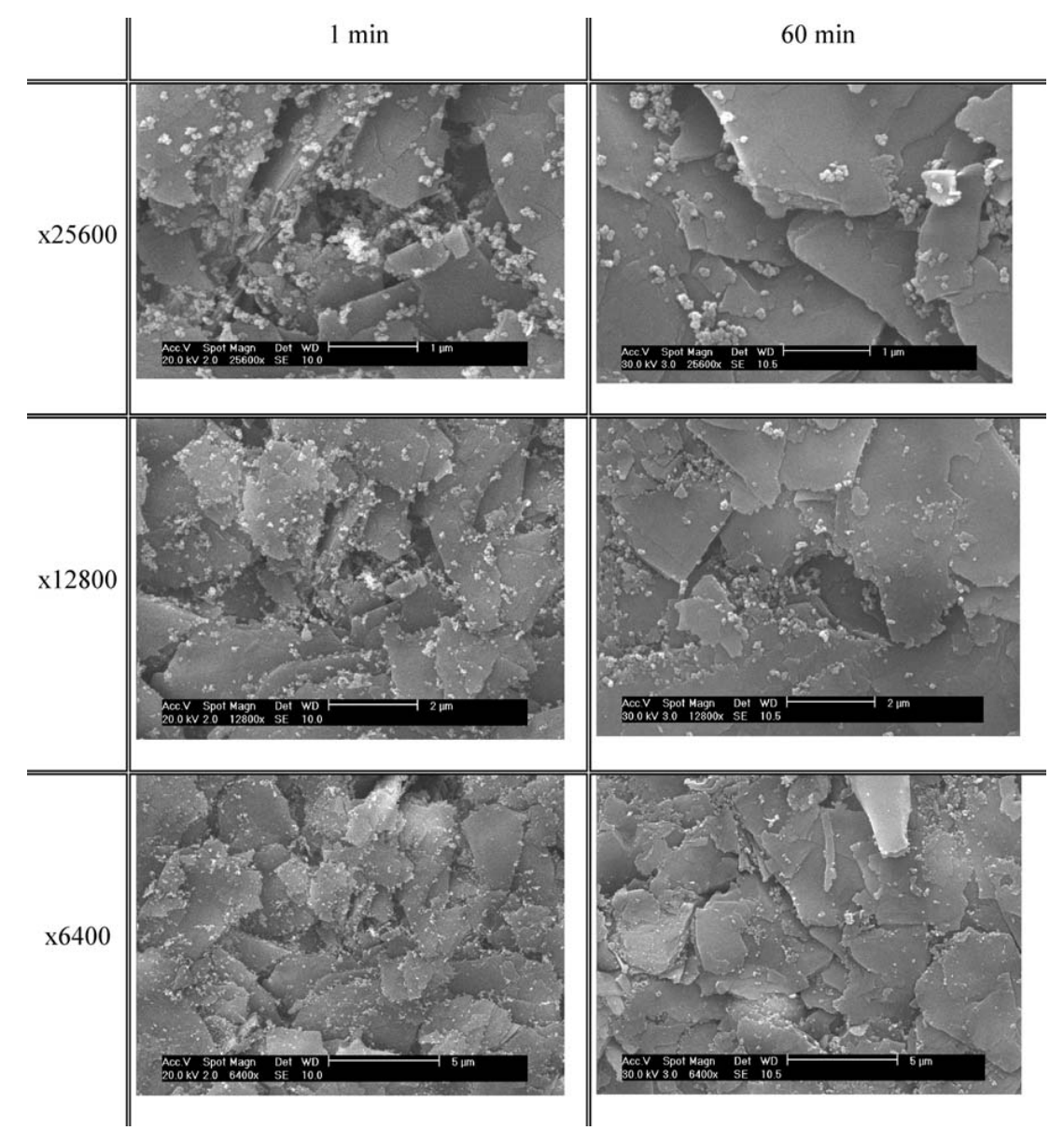

Figure 7. SEM pictures of tablets: comparison of two processing times ( 1 and $60 \mathrm{~min}$ ) at three different magnifications. 
Table 1. Contact Angles and Works of Adhesion as a Function of Silica Concentration (Processing Time: 10 min)

\begin{tabular}{|c|c|c|c|c|c|c|c|c|c|c|c|c|}
\hline $\begin{array}{l}\text { Silica } \\
\text { concentration } \\
(\% \mathrm{w} / \mathrm{w})\end{array}$ & 0 & 0.5 & 1 & 1.5 & 2 & 2.5 & 3 & 4 & 5 & 7 & 10 & $\begin{array}{c}100 \text { (Raw } \\
\text { silica) }\end{array}$ \\
\hline $\begin{array}{l}\text { Contact } \\
\text { angle }\left({ }^{\circ}\right)\end{array}$ & $\begin{array}{r}53.3 \\
\pm 0.2\end{array}$ & $\begin{array}{r}52.4 \\
\pm 0.9\end{array}$ & $\begin{array}{l}53.6 \\
\pm 0.6\end{array}$ & $\begin{array}{r}58.6 \\
\pm 2.1\end{array}$ & $\begin{array}{r}61.4 \\
\pm 1.4\end{array}$ & $\begin{array}{l}72.4 \\
\pm 2.2\end{array}$ & $\begin{array}{l}77.5 \\
\pm 1.5\end{array}$ & $\begin{array}{c}82.4 \\
\pm 1.9\end{array}$ & $\begin{array}{l}103.9 \\
\pm 1.2\end{array}$ & $\begin{array}{l}122.8 \\
\pm 1.6\end{array}$ & $\begin{array}{l}133.4 \\
\pm 2\end{array}$ & $\begin{aligned} & 140.8 \\
\pm & 0.1\end{aligned}$ \\
\hline $\begin{array}{l}\text { Work of } \\
\text { adhesion, } \\
\text { Wa }\left(\mathrm{mJ} / \mathrm{m}^{2}\right)\end{array}$ & $\begin{array}{l}116.3 \\
\pm 1.5\end{array}$ & $\begin{array}{l}117.2 \\
\pm 2.2\end{array}$ & $\begin{array}{r}116 \\
\pm 1.9\end{array}$ & $\begin{array}{l}110.7 \\
\pm 3.5\end{array}$ & $\begin{array}{l}107.7 \\
\pm 2.8\end{array}$ & $\begin{array}{c}94.9 \\
\pm 3.8\end{array}$ & $\begin{array}{l}88.5 \\
\pm 2.8\end{array}$ & $\begin{array}{c}82.4 \\
\pm 3.3\end{array}$ & $\begin{array}{r}55.3 \\
\pm 2.1\end{array}$ & $\begin{array}{r}33.4 \\
\pm 2.1\end{array}$ & $\begin{array}{r}22.8 \\
\pm 2.1\end{array}$ & 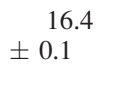 \\
\hline
\end{tabular}

disperse all the particles. This maximum response is referred to as $R \infty$. The sensor response to the dispersion of the powder in a liquid is merely an arbitrary voltage $R$. The signal can be calibrated to give the true concentration of dispersed particles if the dispersion profile has to be developed. For a constant particle size, the extent of dispersion, $X(t)$, is defined as in Eq. 2.

$$
X(t)=\frac{R(t)}{R \infty}=\frac{C(t)}{C \infty}
$$

The stirring speed was $1500 \mathrm{rpm}$ and according to Eq. 3, the corresponding stirring power in the liquid is $1000 \mathrm{~W} / \mathrm{m}^{3}$.

$$
P=N_{\mathrm{P}} \rho N^{3} d^{5}
$$

where $P=$ power dissipated $\left(\mathrm{W} / \mathrm{m}^{3}\right), N_{\mathrm{p}}=$ power number given by the stirrer supplier (1.06), $\rho=$ liquid density (1000 $\left.\mathrm{kg} / \mathrm{m}^{3}\right), N=$ stirring speed $\left(25 \mathrm{~s}^{-1}\right)$, and $d=$ stirrer diameter $\left(35.10^{-3} \mathrm{~m}\right)$.

\section{Results and Discussion Surface morphology}

Effect of the Silica Concentration. The SEM photos (see Figure 5) show a discrete and uniform coating in which all the silica particles play a part. During the observations, no single or agglomerated free silica particles were observed on the support. The increase of the silica concentration on the talc surface appears clearly in these pictures. Some parts of the talc surface remain free for all the samples, except for the $10 \%$ concentration for which almost all the surface is covered by silica.

Even if the talc particles are not spherical, this percentage can be compared with the calculation of $100 \%$ surface coverage of the host particles with a monolayer of guest particles. ${ }^{10}$ For this, we assume that all guest particles are of the same size, both host and guest particles are spherical, and that the host and guest particles do not deform during the coating process. Based on these assumptions, the weight of silica particles $\left(\mathrm{Si}_{\mathrm{wt}} \%\right)$ for $100 \%$ coverage is:

Here:

$$
\mathrm{Si}_{\mathrm{wt}} \%=\frac{N d^{3} \rho_{\mathrm{d}}}{\left(D^{3} \rho_{\mathrm{D}}\right)+\left(N d^{3} \rho_{\mathrm{d}}\right)} \times 100
$$

$$
N=\frac{4(D+d)^{2}}{d^{2}}
$$

From Eq. 4, the weight percentage to coat talc particles ( $D$ $=7 \mu \mathrm{m})$ with nanosilica particles $\left(d_{\text {agglomerates }}=0.250 \mu \mathrm{m}\right)$ is $9.8 \%$, which is in agreement with the SEM observations.
Effect of the Coating Time. The SEM photos for different treatment times (see Figure 6) also show a discrete and uniform coating. As indicated above, at the end of the coating operation, the totality of the powder (talc + Silica) contained in the Cyclomix is recovered and analyzed, so no significant differences should be observed on SEM pictures. However, the coating at very short times (1 and $2 \mathrm{~min}$ ) seems to be different from that at longer times. In fact, from 5 min (see Figures 6c, d), silica particles seem to agglomerate, whereas for 1 and 2 min (see Figures $6 a, b$ ), silica particles are more individualized and cover a bigger surface of the talc particles.

These results are better observed on the SEM pictures of the powder tablets (see Figure 7). When the two extreme times (1 and $60 \mathrm{~min}$ ) are compared, the silica concentration seems to be higher for a processing time of $1 \mathrm{~min}$; whereas, the initial silica concentration in the two samples is the same. These results could be explained by two phenomena: first, the agglomeration of the silica particles and second, the insertion of silica particles in the interstices in the talc particles.

\section{Wettability measurements}

The values of contact angles and work of adhesion as a function of the silica concentration are reported in Table 1 and the corresponding graph is plotted in Figure 8.

The contact angle starts to vary as from $1 \%$ silica concentration. It increases from $53^{\circ}$ for $1 \%$ silica to $140^{\circ}$ for $100 \%$ silica. In the same way, the work of adhesion, characterizing the affinity between the particles and the liquid (water), decreases from 116 to $16 \mathrm{~mJ} / \mathrm{m}^{2}$ with increase of silica concentration. This confirms the increase of the hydrophobicity of the composite particles caused by the presence of hydrophobic silica.

Concerning the effect of the time of coating, Table 2 and Figure 9 show that the contact angle decreases, and, thus,

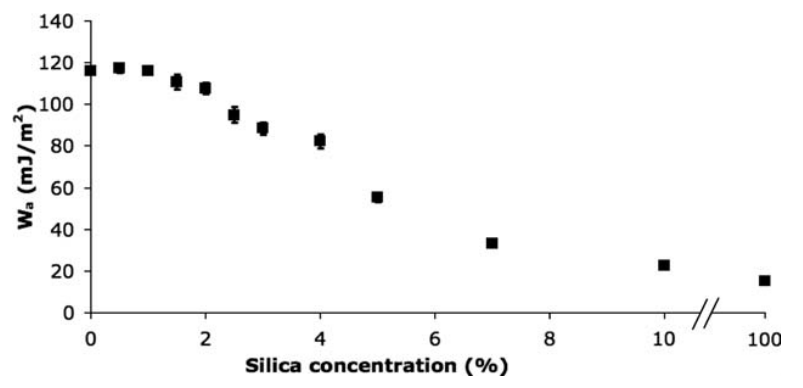

Figure 8. Work of adhesion $W_{a}$ as a function of the silica concentration. 
Table 2. Contact Angles and Works of Adhesion as a Function of Time of Coating (Silica Concentration: 3\%)

\begin{tabular}{|c|c|c|c|c|c|c|c|}
\hline Time $(\min )$ & 1 & 2 & 5 & 10 & 30 & 45 & 60 \\
\hline Contact angle $\left(^{\circ}\right)$ & $113.6 \pm 5.7$ & $103.6 \pm 3.5$ & $73.3 \pm 0.7$ & $77.5 \pm 1.5$ & $60.6 \pm 1.3$ & $60.4 \pm 4.2$ & $56 \pm 2.7$ \\
\hline Work of adhesion, Wa $\left(\mathrm{mJ} / \mathrm{m}^{2}\right)$ & $43.6 \pm 6.8$ & $55.7 \pm 4.9$ & $93.7 \pm 0.4$ & $88.5 \pm 2.8$ & $108.6 \pm 2.7$ & $108.8 \pm 5.9$ & $113.5 \pm 4.1$ \\
\hline
\end{tabular}

the work of adhesion increases when the time of coating increases.

From a coating time of $1 \mathrm{~min}$ to that of $2 \mathrm{~min}$, the work of adhesion increases from 43 to $55 \mathrm{~mJ} / \mathrm{m}^{2}$. Then, for a time of 5 and $10 \mathrm{~min}$, the work of adhesion is about $90 \mathrm{~mJ} / \mathrm{m}^{2}$ and finally seems to reach a plateau at about $110 \mathrm{~mJ} / \mathrm{m}^{2}$ for the times $>10 \mathrm{~min}$. These results are in agreement with the SEM observations, in particular with the agglomeration of the silica particles between the short coating times of 1 and 2 min and the other times. In fact, this agglomeration brings about a decrease in the surface of the hydrophobic silica in contact with the water and thus an increase of the work of adhesion of the composite particles with the water.

\section{Dispersion kinetics}

Effect of the Silica Concentration. Figure 10 shows the dispersion kinetics of the uncoated talc and the talc particles coated with different silica concentrations.

The presence of silica is seen to modify the dispersion kinetics of talc: the higher the silica concentration, the lower is the rate of dispersion. For the $0.5 \%$ silica concentration, the dispersion remains unchanged with respect to that shown by pure talc and complete dispersion is obtained at the same time as with the uncoated particles (about $1200 \mathrm{~s}$ ). When the silica concentration is increased from 1 to $10 \%$, the work of adhesion decreases from 116.3 to $22.8 \mathrm{~mJ} / \mathrm{m}^{2}$ and the dispersion rate, characterized by the slope at the origin $(S)$ of the dispersion kinetics (see Figure 8), decreases from 2.48 to $0.21 \mathrm{~m} / \mathrm{s}$ (see Table 3 ).

For silica concentrations higher than $5 \%$, the general aspect of the dispersion kinetics is changed, and for the $10 \%$ concentration, a threshold value seems to have been reached at which the stirring power used is no longer sufficient to obtain a complete dispersion. For this silica concentration, a plateau is reached at about $80 \%$ dispersion $(20 \%$ of the powder remains at the surface of the water) at between 5000 and

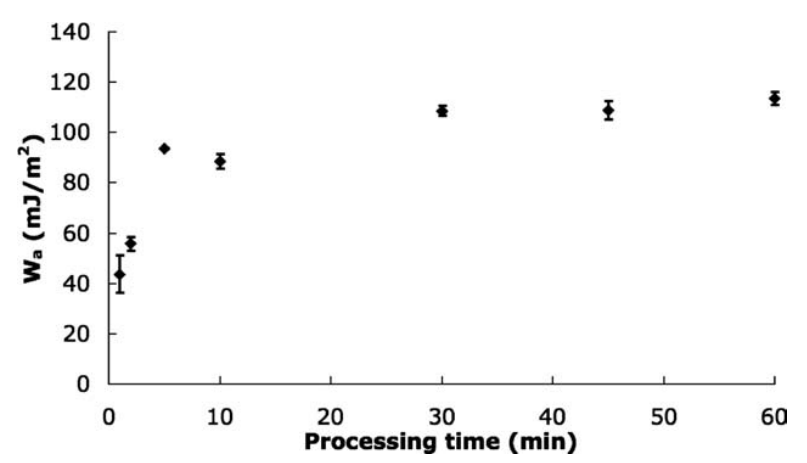

Figure 9. Work of adhesion $W_{a}$ as a function of time of coating.
$7000 \mathrm{~s}$ (not shown in this figure), and the stirring power has to be increased to obtain a total dispersion.

Up to values of $4 \%$ silica concentration, the experimental curves can be fitted (Figures 11 and 12) by a two parameter exponential model given in Eq. 6 and presented elsewhere. ${ }^{3,14,15}$ In this model, $k(\mathrm{~m} / \mathrm{s})$ characterizes the dispersion rate and $A$ corresponds to the final stage of the dispersion. The value of $A$ approaches 1 when all the particles are dispersed in the liquid (see Tables 3 and 4).

$$
X(t)=A\left(1-e^{-k t}\right)
$$

For silica concentrations from 0 to $4 \%$, the decrease in the work of adhesion leads to a decrease in the rate of wetting (and also the rate dispersion) even though wetting is not considered as a "limiting step" at the stirring speed used here. For silica concentrations greater than $4 \%$, the shape of the dispersion kinetics changes, particularly over the first thousand seconds (for example between 0 and $1000 \mathrm{~s}$ for the $10 \%$ concentrations in Figure 10). One of the future objectives will be to develop another model to fit such kinetics, including a parameter characteristic of this limiting wetting step.

Effect of the Coating Time. Figure 13 shows the dispersion kinetics of the talc particles coated with $3 \%$ silica at different times of coating.

The time of coating modifies the dispersion kinetics of talc: the longer the time of coating, the higher is the rate of dispersion $(S)$. In Table 4, a large increase in $S$ can be observed between 1 and 2 min of coating and also between 2 and $5 \mathrm{~min}$. However, for 5 and $10 \mathrm{~min}$ on one hand and for 30 and $45 \mathrm{~min}$ on the other hand, the dispersion curves are rather closer. Finally, for coating produced by the 60 min processing time, we note a new strong increase of the rate of dispersion. Obviously, the time for total dispersion decreases as a function of coating time, however, all the

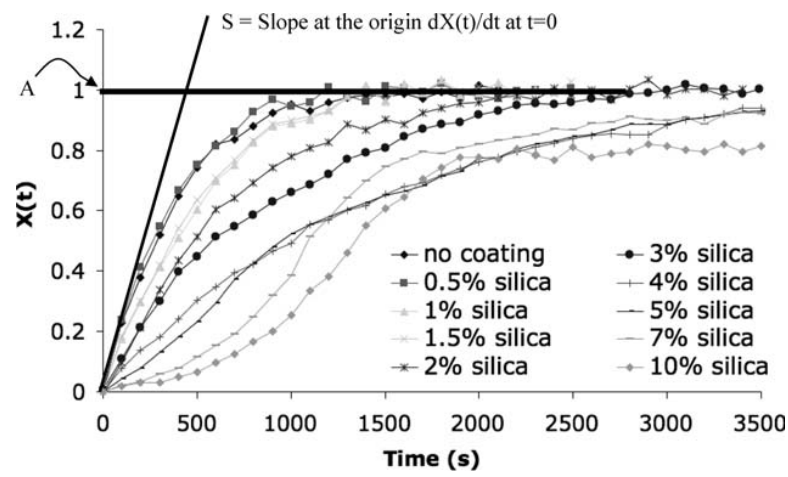

Figure 10. Dispersion kinetics of talc coated with different concentrations of silica. 
Table 3. Slope at the Origin $(S)$ and $A$ as a Function of Silica Concentration (Processing Time: $10 \mathrm{~min}$ )

\begin{tabular}{|c|c|c|c|c|c|c|c|c|c|c|c|}
\hline $\begin{array}{l}\text { Silica } \\
\text { concentration } \\
(\% \mathrm{w} / \mathrm{w})\end{array}$ & 0 & 0.5 & 1 & 1.5 & 2 & 2.5 & 3 & 4 & 5 & 7 & 10 \\
\hline$S(\mathrm{~m} / \mathrm{s})$ & $\begin{array}{c}2.48 \pm \\
0.10\end{array}$ & $\begin{array}{c}2.68 \pm \\
0.39\end{array}$ & $\begin{array}{c}2.01 \pm \\
0.25\end{array}$ & $\begin{array}{c}2.01 \pm \\
0.25\end{array}$ & $\begin{array}{c}1.21 \pm \\
0.31\end{array}$ & $\begin{array}{c}1.36 \pm \\
0.10\end{array}$ & $\begin{array}{c}1.29 \pm \\
0.40\end{array}$ & $\begin{array}{c}0.80 \pm \\
0.23\end{array}$ & $\begin{array}{c}0.46 \pm \\
0.10\end{array}$ & $\begin{array}{c}0.25 \pm \\
0.15\end{array}$ & $\begin{array}{c}0.21 \pm \\
0.10\end{array}$ \\
\hline$A$ & & & & & & & & & & & 0.8 \\
\hline
\end{tabular}

dispersions are total at the stirring power used $\left(1000 \mathrm{~W} / \mathrm{m}^{3}\right)$ and we do not have to increase it.

As shown above for the influence of the silica concentration, the curves can be fitted with the exponential model (see Figure 14).

To summarize the results, the rate of dispersion $(S)$ of composite particles can be plotted as a function of the work of adhesion modified either by the silica concentration or by the processing time (see Figure 15).

Figure 15 shows that, in the range of work of adhesion from 80 to $120 \mathrm{~mJ} / \mathrm{m}^{2}$, a small variation of the work of adhesion leads to a strong change of the rate of dispersion $S$. For instance, in both cases (effect of silica concentration and effect of processing time), when the work of adhesion of the powder increases by $20 \mathrm{~mJ} / \mathrm{m}^{2}$ (from 90 to $110 \mathrm{~mJ} / \mathrm{m}^{2}$ ), it leads to an increase of the rate of dispersion of around $1 \mathrm{~m} / \mathrm{s}$ (from 1.3 to $2.3 \mathrm{~m} / \mathrm{s}$ ). In the range from 20 to $90 \mathrm{~mJ} / \mathrm{m}^{2}$, greater modifications of the work of adhesion are required to have a significant modification of the rate of dispersion. These observations can be highlighted more simply in the case where the work of adhesion is modified by changing the silica concentration. Increasing the silica concentration from 0 to $5 \%$ leads to a strong decrease of the work of adhesion (from 116.3 to $55.3 \mathrm{~mJ} / \mathrm{m}^{2}$ ), which is accompanied by a strong decrease in the rate of dispersion from 2.48 to 0.46 $\mathrm{m} / \mathrm{s}$. The same increase of $5 \%$ in the silica coating (from 5 to $10 \%$ ) leads to a smaller decrease of the work of adhesion

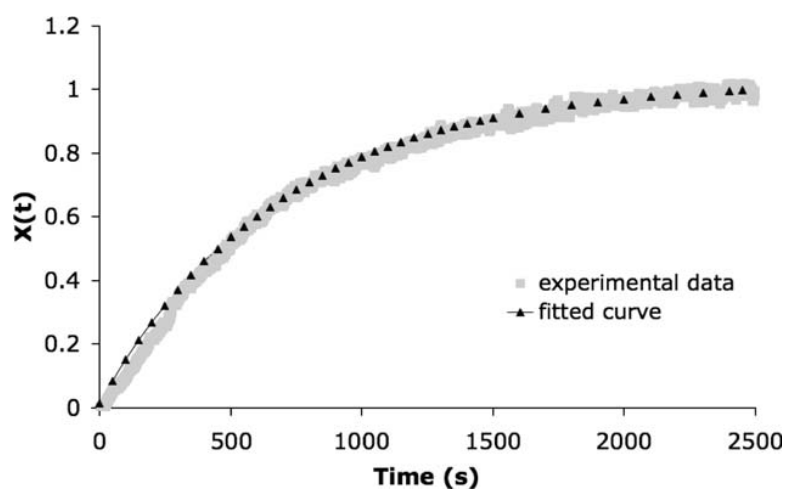

Figure 11. Correlation between experimental data and the fitted curve ( $2 \%$ silica concentration -10 min). from 55.3 to $22.8 \mathrm{~mJ} / \mathrm{m}^{2}$ and a smaller decrease in the rate of dispersion (from 0.46 to $0.21 \mathrm{~m} / \mathrm{s}$ ). Thus, the initial modification of the surface of talc, characterized by small additions of coating silica $(0.5-4 \%)$, has a strong influence on the rate of dispersion, whereas the influence of larger quantities of silica $(5-10 \%)$ on $S$ is less.

Be that as it may, whatever the method used to modify the work of adhesion between the talc particles and the water, this work of adhesion calculated from the contact angle measurements seems to give a good characterization of the rate of dispersion of talc particles in water.

\section{Conclusions and Perspectives}

This study indicates that it is possible to change the dispersion properties of talc particles by coating them with hydrophobic silica (Aerosil R972 ${ }^{\circledR}$ ) using a Cyclomix as dry coating device. This results in a discrete coating of silica on the surface of talc particles and makes talc more hydrophobic, as confirmed by measurements of the work of adhesion performed by the sessile drop method on powder tablets. The modification of the work of adhesion can be directly linked to the slope at the origin $S$ of the dispersion kinetics of the powder in water, which is a characteristic of the rate of dispersion. When the work of adhesion decreases, the rate of dispersion decreases and this effect is more important for

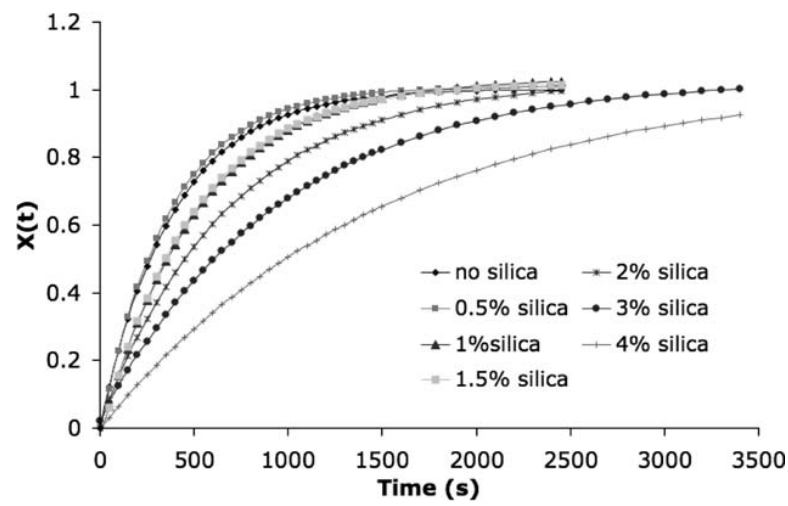

Figure 12. Fits of the kinetics for the influence of the silica concentration (up to the $4 \%$ concentration).

Table 4. Slope at the Origin $(S)$ and $A$ as a Function of Processing Time (Silica Concentration: 3\%)

\begin{tabular}{lccccccc}
\hline Time $(\mathrm{min})$ & 1 & 2 & 5 & 10 & 30 & 60 \\
\hline$S(\mathrm{~m} / \mathrm{s})$ & $0.57 \pm 0.17$ & $1.01 \pm 0.30$ & $1.73 \pm 0.07$ & $1.29 \pm 0.40$ & $2.23 \pm 0.23$ & $2.03 \pm 0.55$ & $3.26 \pm 0.53$ \\
$A$ & & & & & & & \\
\hline
\end{tabular}




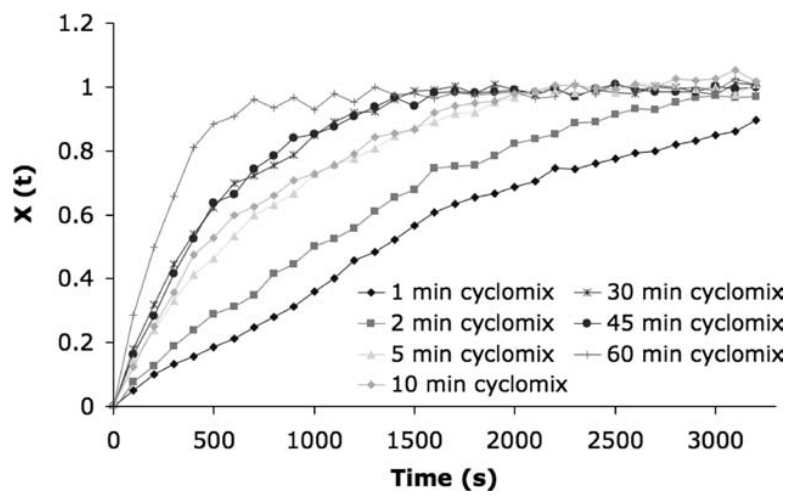

Figure 13. Dispersion kinetics of talc coated at different processing times.

the higher values of work of adhesion (between 90 and 120 $\mathrm{mJ} / \mathrm{m}^{2}$ ), where a small decrease can lead to a strong decrease of the rate of dispersion.

Two methods have been used to modify the work of adhesion, either changing the silica concentration or changing the processing time for coating. In the first case, as would be expected the work of adhesion decreases when the concentration of hydrophobic silica increases. When the processing time is increased, the work of adhesion also increases. SEM photos bring a first indication as to the effect of the time of coating. For the shorter times ( 1 and $2 \mathrm{~min}$ ), the silica particles seem to cover a bigger part of the talc surface and for the processing times $>2 \mathrm{~min}$, the silica particles seem to agglomerate and may insert into the interstices of the talc sheets. Thus, by increasing the processing time, the surface of hydrophobic silica at the interface powder/water becomes less and the work of adhesion increases.

This study represents a new approach for the use of physical chemistry, in particular, the work of adhesion, for processing and formulation of powder products. In the future, we will try to find other ways to modify the work of adhesion between talc and liquid, by modifying the talc surface and/or the surface tension of the liquid, to confirm its influence on the rate of dispersion.

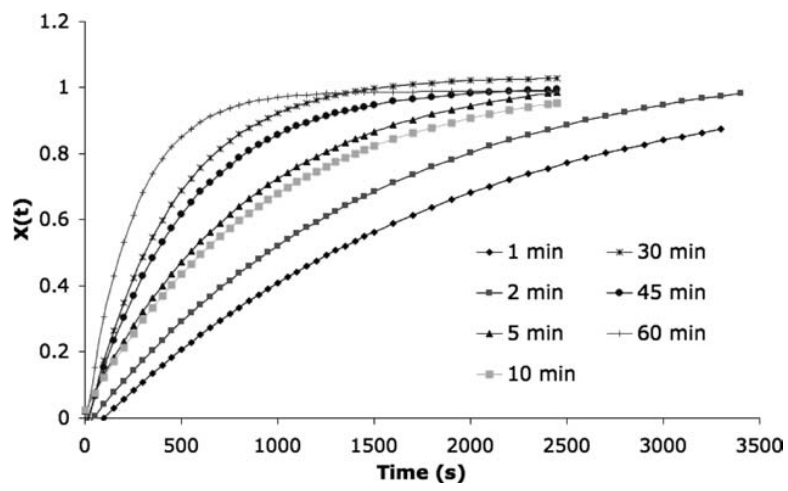

Figure 14. Fits of the kinetics for the influence of time of coating.

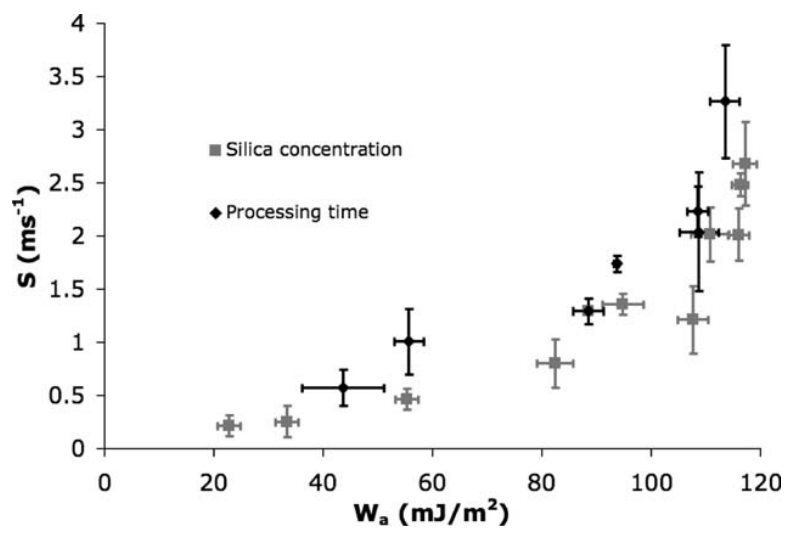

Figure 15. Slope at the origin (S) as a function of the work of adhesion of talc particles.

\section{Acknowledgments}

The authors thank Aurélie Clément and Philippe Accart for their technical support.

\section{Literature Cited}

1. Trambouze PVLHWJP. Les réacteurs chimiques: conception, calcul, mise en oeuvre. Paris: Technip, 1984.

2. Xuereb C, Poux M, Bertrand J. Agitation et mélange-aspects fondamentaux et applications industrielles. Paris: Dunod, 2006.

3. Galet L, Goalard C, Dodds JA. The importance of surface energy in the dispersion behaviour of talc particles in aqueous media. Powder Technol. 2009;190:242-246.

4. Saxena A, Kendrick J, Grimsey I, Mackin L. Application of molecular modelling to determine the surface energy of mannitol. Int $J$ Pharm. 2007;343:173-180.

5. Tavana H, Neumann AW. Recent progress in the determination of solid surface tensions from contact angles. Adv Colloid Interface Sci. 2007;132:1-32.

6. Ahadian S, Mohseni M, Moradian S. Ranking proposed models for attaining surface free energy of powders using contact angle measurements. Int J Adhes Adhes. 2009;29:458-469.

7. Ouabbas Y, Chamayou A, Galet L, Baron M, Thomas G, Grosseau R, Guilhot B. Surface modification of silica particles by dry coating: characterization and powder ageing. Powder Technol. 2009;190:200-209.

8. Ouabbas Y, Dodds J, Galet L, Chamayou A, Baron M. Particle-particle coating in a cyclomix impact mixer. Powder Technol. 2009;189:245-252.

9. Thomas G, Ouabbas Y, Grosseau P, Baron M, Chamayou A, Galet L. Modeling the mean interaction forces between powder particles. Application to silica gel-magnesium stearate mixtures. Appl Surf Sci. 2009;255:7500-7507.

10. Yang J, Sliva A, Banerjee A, Dave RN, Pfeffer R. Dry particle coating for improving the flowability of cohesive powders. Powder Technol. 2005;158:21-33.

11. Pfeffer R, Dave RN, Wei DG, Ramlakhan M. Synthesis of engineered particulates with tailored properties using dry particle coating. Powder Technol. 2001;117:40-67.

12. Bergougnoux L, Misguich-Ripault J, Firpo JL. Characterization of an optical fiber bundle sensor. Rev Sci Instrum. 1998;69:1985-1990.

13. Goalard C. Etude physico-chimique du procédé de dispersion des poudres libres et agglomérées en milieu liquide. France: Albi: Ecole des Mines d'Albi-Carmaux, 2005.

14. Kravtchenko TP, Renoir J, Parker A, Brigand G. A novel method for determining the dissolution kinetics of hydrocolloid powders. Food Hydrocolloids. 1999;13:219-225.

15. Larsen CK, Gaserod O, Smidsrod O. A novel method for measuring hydration and dissolution kinetics of alginate powders. Carbohydr Polym. 2003;51:125-134. 